
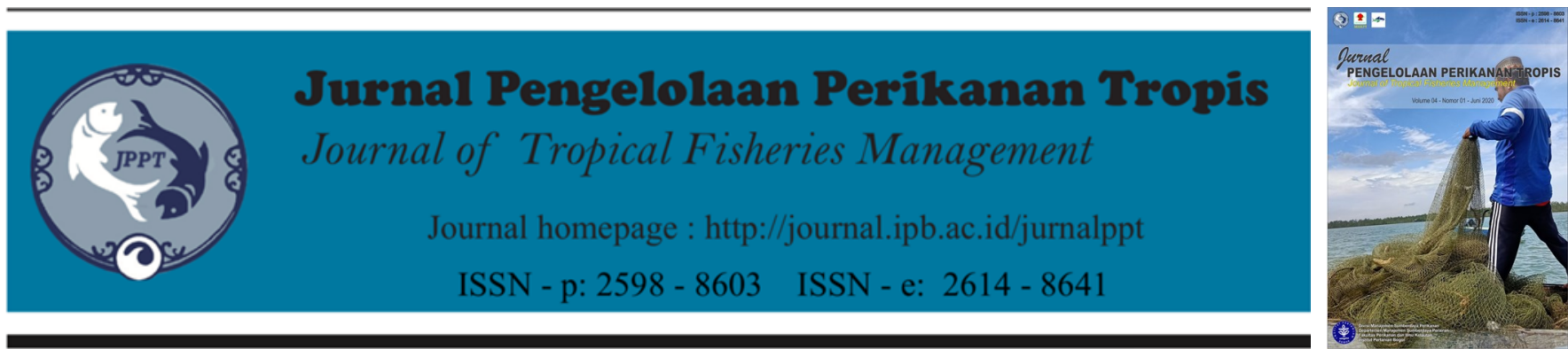

\title{
Produktivitas Sekunder Organisme Bentik (Ordo Diptera) di Sungai Cigambreng, Desa Tapos, Kecamatan Tenjolaya, Kabupaten Bogor, Jawa Barat
}

\author{
(Productivity of Bentic Organisms (Order Diptera) in Cigambreng River, Tapos Village, Subdistrict \\ Tenjoloya, Bogor Regency, West Java)
}

\section{Rizky Regina Kawirian ${ }^{1 *}$, Arif Nurcahyanto ${ }^{1}$, Didit Abdillah ${ }^{1}$, Grin Tommy Panggabean ${ }^{1}$, Muhammad Irfan Afif ${ }^{1}$, Ahyar Pulungan ${ }^{1}$, Chichilia Qaila A. Rahman ${ }^{1}$, Mursalin Ishak ${ }^{1}$, Majariana Krisanti $^{2}$}

${ }^{1}$ Program Studi Pengelolaan Sumberdaya Perairan, Sekolah Pasca Sarjana, IPB University

${ }^{2}$ Departemen Manajemen Sumberdaya Perairan, Fakultas Perikanan dan Ilmu Kelautan, IPB University

\begin{abstract}
ARTIKEL INFO
Article History

Recevied: 25 April 2020

Accepted: 29 Mei 2020

\section{Kata Kunci:}

diptera, produktivitas sekunder, sungai cigambreng

Keywords:

\section{ABSTRAK}

Insekta memiliki biodiversitas dengan penyebaran yang luas diseluruh dunia. Penelitian ini bertujuan untuk mengetahui produktivitas sekunder dari organisme bentik (Ordo Diptera) di Sungai Cigambreng menggunakan rasio P/B. Pengambilan Sampel mingguan dilakukan bulan Oktober 2019. Ditemukan total 717 individu Ordo Diptera yang melingkupi dua famili di Sungai Cigambreng. Tiap famili yang diperoleh melingkupi satu jenis yakni Antocha sp. (Famili Tipulidae.) dan Krenopelopia sp. (Chironomidae). Kehadiran jenis chironomid mengindikasikan adanya beban masukan berlebihan (Polutan) ke dalam perairan sungai Cigambreng. Secara umum, kepadatan tertinggi diperoleh pada pengamatan ke empat yakni $284 \mathrm{ind} / \mathrm{m}^{2}$, sedangkan kepadatan terendah diperoleh pada pengamatan ke dua yakni $60 \mathrm{ind} / \mathrm{m}^{2}$. Produktivitas sekunder berdasarkan rasio P/B sebesar 3.034/bulan dengan kecepatan produksi $14.2458\left(\mathrm{~g} / \mathrm{m}^{2} / \mathrm{bln}\right)$ dan biomassa $\left(4.6954 \mathrm{~g} / \mathrm{m}^{2}\right)$.
\end{abstract}

diptera, secondary productivity,

cigambreng river

\section{Korespondensi Author}

Rizky Regina Kawirian,

Program Studi Pengelolaan Sumberdaya Perairan, Fakultas Perikanan dan Ilmu Kelautan, Institut Pertanian Bogor. Email:

rizkyrginkawiran12@gmail.com

\section{ABSTRACT}

Insekts has biodiversity with a wide distribution throughout the world. The aims of this research were to determine the secondary productivity of benthic organism (Order Diptera) in Cigambreng River using a P/B ratio. Sampling was carried out once a weeks during October 2019. A total 717 individual of Order Diptera were found which covered two families in the Cigambreng River. Each family obtained includes one type, Antocha sp. (Family Tipulidae.) and Krenopelopia sp. (Chironomidae). The presence of a chironomid has indicates an excessive input load (pollutant) into the waters of the Cigambreng River. In general, the highest density was obtained at the fourth observation, $284 \mathrm{ind} / \mathrm{m} 2$, while the lowest density was obtained at the second observation, which was $60 \mathrm{ind} / \mathrm{m} 2$. Secondary productivity covers $P / B$ ratio of 3.034 /month with a production speed of $14.2458\left(\mathrm{~g} / \mathrm{m}^{2} /\right.$ month) and biomass $\left(4.6954 \mathrm{~g} / \mathrm{m}^{2}\right)$.

\section{PENDAHULUAN}

Produksi merupakan aliran energi atau perubahan massa atau energi dari waktu kewaktu dan memiliki dimensi massa per wilayah yang dibentuk selama periode waktu tertentu $\left(\mathrm{g} / \mathrm{m}^{2} /\right.$ tahun) (Wetzel 2001). Sedangkan, biomassa didefinisikan sebagai massa dari organisme pada area tertentu yang melingkupi daratan atau perairan yang diekpresikan pada unit energi $(\mathrm{J} /$ $\mathrm{m}^{2}$ ) atau bahan organik kering (ton/hektar) (Townsend et al. 2008). Rasio P/B dapat digunakan untuk mengestimasi laju perubahan organisme dan untuk semua tingkat trofik hingga memberikan indek umum dari kecepatan relatif aliran energi hingga biomassa (Wetzel 2001). Produktivitas sekunder merupakan kecepatan produksi biomassa oleh heterotrof (Begon et al. 2006). Perhitungan produktivitas sekunder pada hewan didasarkan pada perubahan jumlah, biomassa, dan kecepatan pertumbuhan (Wetzel 2001).

Serangga akuatik dapat digunakan sebagai model dalam menganalisis struktur dan fungsi dari ekosistem air tawar disebabkan oleh kelimpahan yang tinggi, kecepatan pertumbuhan yang tinggi dengan masa hidup yang pendek, biomassa besar dan proses kolonisasi yang cepat 
pada habitat air tawar (Solanki \& Shukla 2015). Keberadaan serangga akuatik dari famili tertentu dapat mengindikasi kesehatan perairan (Choudary \& Ahi 2015). Salah satu dari jenis serangga akuatik adalah ordo Diptera. Representasi dari Diptera (lalat, nyamuk, dan asosiasinya) merupakan serangga holometabola yang dibedakan dengan serangga lainnya melalui kehadiran sepasang sayap fungsional pada dewasa. Karakter inilah yang mendasari nama diptera (di: dua; ptera: sayap) (Fusari et al. 2018).

Diptera (lalat bersayap dua) merupakan kelompok serangga mayor. Larva diptera memiliki kemampuan memproses bahan organik dan cakupannya adalah chironomids yang beragam, tipulid yang merusak dedaunan dan larva lalar hitam yang merupakan serangga yang memperoleh nutrisi dengan cara menyaring makanan (filter-feeding) (Moss 2018). Larva Diptera ditemukan pada semua tipe habitat akuatik, dan merupakan famili terbanyak yang bersifat akuatik atau semi akuatik (31 famili) dibandingkan dengan ordo serangga air lainnya (Clifford 1991; Fusari et al. 2018). Beberapa larva diptera juga dapat mentoleransi oksigen terlarut yang rendah, kondisi salinitas yang tinggi, dan beberapa dapat bertahan hidup pada pada mata air panas (Clifford 1991). Sebagai contoh larva chironomid mampu bertahan pada zona profundal yang merupakan zona konsentrasi oksigen terlarut menjadi terbatas untuk sebagian besar invertebrate, dan hanya beberapa predator yang dapat bertahan (Boulton et al. 2014).

Salah satu ekosistem akuatik yang ada di Kabupaten Bogor adalah Sungai Cigambreng yang berlokasi pada kecamatan Tenjolaya. Kecamatan Tenjolaya sendiri merupakan salah satu kecamatan di Kabupaten Bogor yang memiliki luas 23,83 $\mathrm{m}^{2}$ (BPS Kabupaten Bogor 2019). Sungai Cigambreng dimanfaatkan oleh masyarakat setempat untuk sumber pengairan persawahan, mencuci pakaian serta dari sisi ekologi merupakan tempat terjadinya proses interaksi antar hewan-hewan akuatik. Sehingga, kajian tentang produktivitas sekunder di daerah Sungai Cigambreng penting untuk dilakukan sebagai salah satu aspek pertimbangan dalam pengelolaan sungai tersebut.

\section{METODE}

\section{Waktu dan Lokasi Penelitian}

Pengambilan data dilakukan empat kali selama satu bulan (tanggal 5, 12, 20, dan 29 Oktober 2019) di Sungai Cigambreng yang merupakan salah satu sungai yang menjadi bagian DAS Cisadane yang terdapat di Desa Tapos, Kec. Tenjolaya, Kab. Bogor (Gambar 1).

Empat stasiun dipilih dengan karakteristik riffle area yang berjarak 100 meter antar stasiun pengambilan contoh organisme bentik pada tiap stasiun menggunakan surber dengan tiga sub stasiun. Secara geografis DAS Cisadane terletak pada $106^{0} 20^{\prime} 50^{\prime \prime}-106^{\circ} 28^{\prime} 20^{\prime \prime}$ BT dan $6^{0} 0^{\prime} 59^{\prime \prime}$ $6^{0} 47^{\prime} 02$ "LS. Berdasarkan citra DEM, luas DAS Cisadane adalah $1.372,34 \mathrm{~km}^{2}$ dengan panjang sungai utama adalah 292,71 km (Junaidi 2014).

\section{Analisis Contoh}

Pengamatan dan identifikasi dilakukan di Laboratorium Biologi Mikro 1, Departemen Manajemen Sumberdaya Perairan, Fakultas Perikanan dan Ilmu Kelautan, IPB University. Identifikasi spesies dilakukan berdasarkan ciri morfologi yang tampak dengan mengacu pada: Clifford (1991), Kriska (2014), dan Hamada et al. (2018).

\section{Analisis Data}

Estimasi produktivitas sekunder terlepas dari pendekatan apapun membutuhkan pengukuran akurat dari kepadatan dan struktur ukuran populasi (Benke \& Huryn 2007). Kepadatan dihitung menggunakan rumus (Priyono 2012):

$$
\mathrm{Ki}=(\mathrm{ni} / \mathrm{L}) \times 10000
$$

Dimana:

$$
\begin{array}{ll}
\mathrm{Ki} & =\text { Kepadatan jenis ke-I }\left(\mathrm{Ind} / \mathrm{m}^{2}\right) \\
\mathrm{ni} & =\text { Jumlah individu jenis ke } \mathrm{i} \\
\mathrm{L} & =\text { Luas bukaan surber }(30 \times 30) \\
10000 & =\text { Nilai konversi dari } \mathrm{cm}^{2} \mathrm{ke} \mathrm{\textrm {m } ^ { 2 }}
\end{array}
$$

Jumlah biomassa untuk semua ukuran kelompok merupakan biomassa populasi (Benke \& Huryn 2007). Penentuan biomassa dilakukan dengan menghitung biomassa per selang kelas. Bobot diperoleh dengan menggunakan pendekatan biovolume dengan mengasumsi tubuh larva sebagai tabung. Sehingga dapat dihitung menggunakan rumus:

$$
\text { Biomassa }=\pi \times \mathrm{L}_{\mathrm{t}} \times \mathrm{W}_{\mathrm{t}}^{2}
$$

\section{Dimana: \\ $\pi=3.14$ \\ $\mathrm{L}_{\mathrm{t}}=$ panjang total \\ $\mathrm{W}_{\mathrm{t}}=$ lebar total}

Analisis produktivitas sekunder dilakukan dengan pendekatan non-Cohort disebabkan populasi larva tidak diketahui pola perkembangan dalam siklus hidupnya sebagai suatu kohort pada data lapangan. Teknik non Cohort dapat dilakukan dengan dua cara yakni:

Metode Frekuensi Ukuran, yang dihitung dengan menggunakan rumus Hynes \& Coleman (1968) yang sudah dimodifikasi oleh Benke \& Huryn (2007), dengan formula sebagai berikut: 


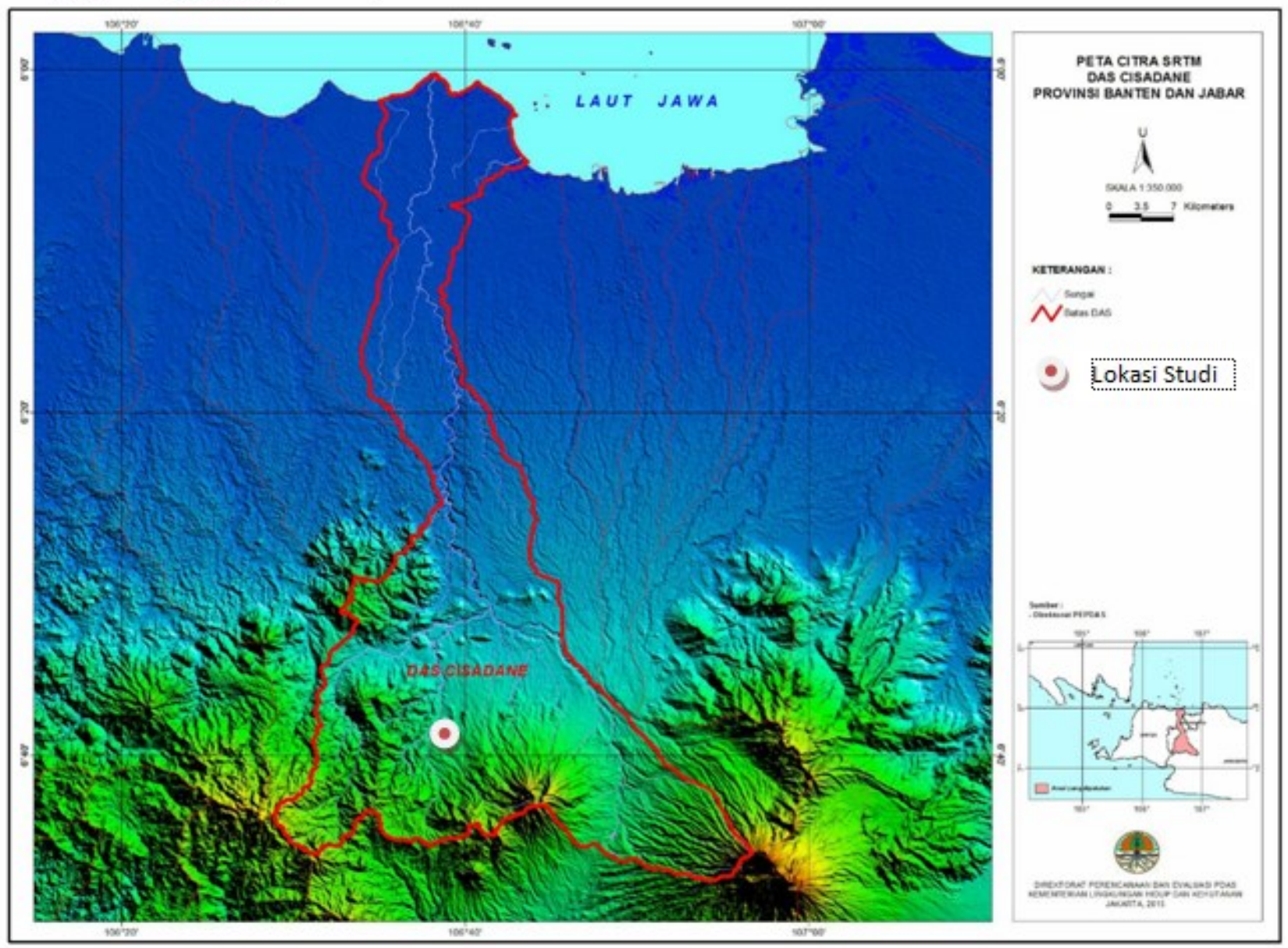

Gambar 1. Area studi di Sungai Cigambreng, yang merupakan bagian DAS Cisadane (Sumber:DIT PEPDAS, 2015 dengan modifikasi).

$$
\mathrm{P}=\left[\mathrm{i} \times \sum\left(\mathrm{n}_{\mathrm{j}}-\mathrm{n}_{\mathrm{i}}+1\right) \times\left(\left(\mathrm{W}_{\mathrm{j}}+\mathrm{W}_{\mathrm{j}}+1 / 2\right]\right.\right.
$$

\section{keterangan:}

$$
\begin{array}{ll}
\mathrm{P} & =\text { Produktivitas sekunder tahunan }(\mathrm{g} \\
& \left.\mathrm{m}^{-2} \mathrm{bln}^{-1}\right) ; \\
\mathrm{I} & \text { Jumlah kelas ukuran; } \\
\mathrm{I} & \text { Selisih kepadatan individu kelas } \\
& \text { ukuran ke-j dikurangi kelas } \\
& \text { ukuran ke- }(\mathrm{j}+1) ; \\
& \\
\left(\mathrm{n}_{\mathrm{i}} \mathrm{x} \mathrm{W}_{\mathrm{j}}+1\right)= & \text { rerata geometri berat dari dua } \\
& \text { kelas ukuran. }
\end{array}
$$

\section{HASIL DAN PEMBAHASAN}

\section{Hasil}

\section{Kelimpahan Ordo Diptera}

Hasil identifikasi menunjukkan ordo Diptera di Sungai Cigambreng terdiri dari dua famili yakni tipulidae (Antocha sp.) dan chironomidae (Krenopelopia sp.). Secara umum, kelimpahan tertinggi diperoleh pada pengamatan ke empat yakni $284 \mathrm{ind} / \mathrm{m}^{2}$, sedangkan kelimpahan terendah diperoleh pada pengamatan ke dua yakni $60 \mathrm{ind} / \mathrm{m}^{2}$. Jenis Antocha sp. menunjukkan kelimpahan yang lebih tinggi dibanding dengan Krenopelopia sp. pada pengamatan I (149 ind/ $\left.\mathrm{m}^{2}\right)$, II (40 ind $\left./ \mathrm{m}^{2}\right)$ dan IV (163 ind $\left./ \mathrm{m}^{2}\right)$. Sedangkan, kemelimpahan yang tinggi dari jenis Krenopelopia sp. diperoleh pada pengamatan III yakni $124 \mathrm{ind} / \mathrm{m}^{2}$ dibanding Antocha sp. (27 ind/ $\mathrm{m}^{2}$ ) (Gambar 2).

\section{Produktivitas Sekunder}

Nilai perbandingan produksi per biomassa $(\mathrm{P} /$ B Rasio) Ordo Diptera yakni 3.034/bulan dengan nilai produksi ordo Diptera yakni $14.2458\left(\mathrm{~g} / \mathrm{m}^{2} /\right.$ bln) dan biomassa $\left(4.6954 \mathrm{~g} / \mathrm{m}^{2}\right)$ (Tabel 1).

\section{Pembahasan}

Sungai Cigambreng memiliki karakteristik sungai berbatu dengan ukuran besar hingga kecil, dengan dasar perairan berpasir. Dua famili ditemukan yakni Tipulidae (Antocha sp.) dan Chironomidae (Krenopelopia sp.). Famili Chironomidae merupakan famili dari ordo Diptera yang memiliki penyebaran paling luas, beragam, dan yang paling melimpah dari seluruh famili makroinvertebrata bentik pada ekosistem akuatik terutama sungai pengunungan (Scheibler et al. 2014), dan melingkupi estuari dan ekosistem pesisir laut (Kranzfelder \& Ferrington 2018). Diversitas tinggi jenis chironomid 
Tabel 1. Produktivitas Sekunder Ordo Diptera di Sungai Cigambreng

\begin{tabular}{lccc}
\hline \multirow{2}{*}{ Ordo } & \multicolumn{3}{c}{ Size Frequency Method $(\mathrm{SF})$} \\
\cline { 2 - 4 } & Produksi $\left(\mathrm{g} / \mathrm{m}^{2} / \mathrm{bln}\right)$ & Biomass $\left(\mathrm{g} / \mathrm{m}^{2}\right)$ & $\mathrm{P} / \mathrm{B}$ Kohort \\
\hline Diptera & 14.2458 & 4.6954 & 3.034 \\
\hline
\end{tabular}

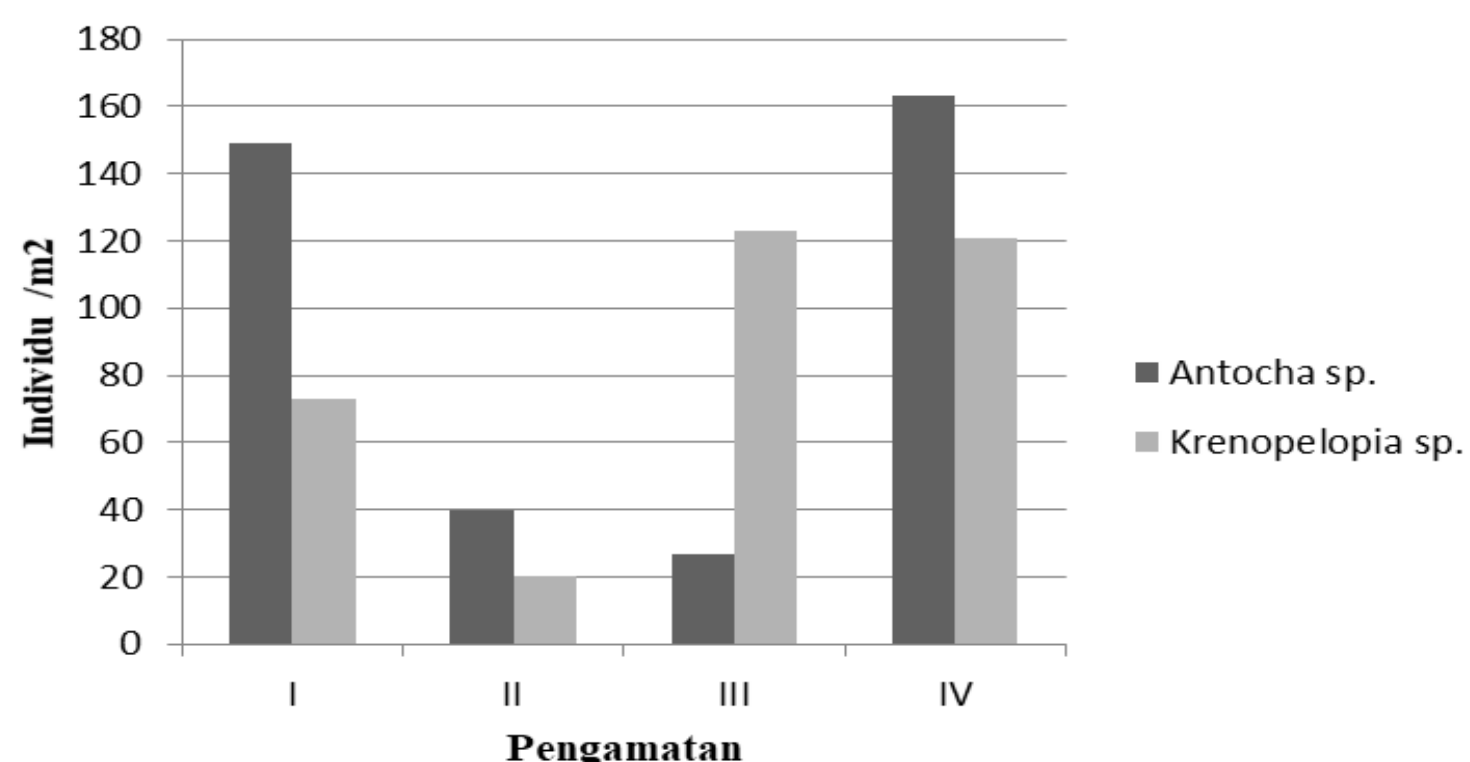

Gambar 2. Kepadatan ordo Diptera di Sungai Cigambreng

ditemukan pada habitat sungai yang berkarakteristik bebatuan, kerikil dan berpasir (Butakka et al. 2014). Beberapa spesies chironomid dapat dijadikan indikator yang dapat diandalkan terkait dengan faktor biologi dan fisika kimia sungai pegunungan (Kawai et al. 2014). Chironomidae merupakan organisme yang sangat toleran pada banyak sistem perairan air tawar (Arslan et al. 2010). Namun aktivitasnya larvanya sangat dipengaruhi oleh kualitas nutrisi serasa (Rossi et al. 2015). Sedangkan, Antocha sp. termasuk jenis yang ditemukan melimpah pada hulu sungai dibanding dengan jenis famili Tipulidae yang lainnya (Hirabayashi et al. 2007).

Famili Tipulidae memiliki peran besar dalam rantai makanan, Tipula paludosa merupakan salah satu spesies dari famili Tipulidae yang menjadi makanan yang penting bagi beberapa serangga, ikan dan burung (Desai et al. 2014). Kehadiran hanya dua jenis dari ordo Diptera yang ditemukan di sungai Cigambreng menunjukkan adanya indikasi pencemaran. Hal ini kemungkinan disebabkan buangan dari peternakan ayam yang berada disekitar bantaran sungai. Bayo \& Wyckhuys (2019) menyatakan diantara serangga akuatik, spesies yang toleran terhadap polutan akan menggantikan hilangnya biodiversitas yang besar di perairan yang berdekatan dengan pertanian dan pemukiman.

Kemelimpahan Ordo Diptera di Sungai Cigambreng menunjukkan fluktuasi (Gambar 2).
Kepadatan Antocha sp. menurun secara signifikan pada pengamatan I hingga pengamatan III yakni $149 \mathrm{ind} / \mathrm{m}^{2}$ menjadi $47 \mathrm{ind} / \mathrm{m}^{2}$. Namun, kembali meningkat pada pengamatan ke IV $\left(163 \mathrm{ind} / \mathrm{m}^{2}\right)$. Pola yang sama ditunjukkan oleh Krenopelopia sp. walaupun pada pengamatan I, II, dan IV jumlah Krenopelopia sp lebih rendah dibanding Antocha sp. Hal ini kemungkinan disebabkan oleh perubahan kondisi lingkungan selama proses pengambilan sampel yakni turunnya hujan sehari sebelum pengambilan data pada pengamatan II dan III. Sehingga organisme banyak yang hanyut terbawa arus aliran air. Floss et al. (2013) menyatakan variasi dominansi, kemelimpahan, dan kekayaan spesies di akibatkan oleh karakteristik lingkungan, yang melingkupi kehadiran vegetasi tepian dan substrat yang heterogen dan juga aktivitas manusia.

Produktivitas sekunder mengacu pada akumulasi bahan organik oleh organisme heterotrof per unit area per unit waktu (Majagi et al. 2003). Kohort P/B ordo Diptera pada sungai Cigambreng memiliki nilai sebesar 3.034/Bulan (Tabel 1). Anbalagan et al. (2014) memperoleh hasil perbedaan rasio $\mathrm{P} / \mathrm{B}$ yang lebih tinggi pada empat taksa yang diperoleh yakni $L$. nuburagangai (4.8), Baetis sp. (8.3), $C$. alagarensis (8.4), dan N. biseriata (8.9). Benke \& Huryn (2007) menjelaskan bahwa Kohort P/B pada dasarnya adalah nilai rata-rata tertimbang dari tingkat pertumbuhan biomassa semua 
individu dalam populasi yang menunjukkan produksi populasi selama rentang hidupnya yang dibagi dengan biomassa rata-rata selama periode yang sama. Produksi chironomid pada sungai English mendukung bahwa masa hidup jenis ini pendek yakni $<2$ minggu (Mackey 1977). Penelitian awal mengenai estimasi produksi pada interval waktu yang singkat (dalam setahun) memberikan pemahaman yang tinggi terkait dengan dinamika populasi dan sumberdaya potensial dibanding dengan periode yang lama (Benke \& Huryn 2010). Nilai produksi ordo Diptera pada penelitian ini diperoleh sebesar $14.2458\left(\mathrm{~g} / \mathrm{m}^{2} / \mathrm{bln}\right)$ dengan biomassa $(4.6954 \mathrm{~g} /$ $\mathrm{m}^{2}$ ). Nilai ini lebih tinggi dibandingkan dengan estimasi laju produksi kolektor makroinvertberata pada aliran sungai di Arizona yakni $135 \mathrm{~g} / \mathrm{m}^{2} /$ tahun atau $11.25 \mathrm{~g} / \mathrm{m}^{2} /$ bulan (Fisher \& Gray 1983).

\section{KESIMPULAN DAN SARAN}

\section{Kesimpulan}

Pada Penelitian ini komposisi Ordo Diptera yang ditemukan di Sungai Cigambreng terdiri dari dua spesies dari famili yang berbeda dari yakni Famili Tipulidae (Antocha sp.) dan Chironomidae (Krenopelopia sp.). Badan air sungai terindikasi mengalami pencemaran yang ditandai dengan kehadiran jenis chironomid.

\section{Saran}

Diperlukan kajian lebih mendalam terkait dengan kondisi lingkungan yang mempengaruhi kemelimpahan spesies yang ditemukan di penelitian ini, dan dampak pertanian disekitar sungai terhadap kehadiran spesies pada dua musim berbeda.

\section{DAFTAR PUSTAKA}

Anbalagan S, Dinakaran S, Krishnan M. 2014. Life cycle and secondary production of four species from functional feeding groups in a tropical stream of South India. International Journal of Zoology. 1-8.

Arslan N, Ayık Ö, Şahin Y. 2010. Diversity and structure of Chironomidae (Diptera) Limnofauna of Lake Uluabat, a Ramsar Site of Turkey, and their Relation to Environmental Variables. Turkish Journal of Fisheries and Aquatic Sciences. 10: 315-322.

Bayo FS, Wyckhuys KAG. 2019. Worldwide decline of the entomofauna: A review of its drivers. Biological Conservation. 232: 8-27.

Begon M, Townsend CR, Harper JL. 2006. Ecology from Individual to Ecosystem (Fourth Edition). USA: Blackwell Publishing.

Benke AC, Huryn AD. 2007. Secondary production of macroinvertebrates. In: Hauer
FR, Lamberti GA (Eds.). Methods in Stream Ecology. (Second Edition). Amsterdam: Elsevier Inc.

Benke AC, Huryn AD. 2010. Benthic invertebrate production-facilitating answers to ecological riddles in freshwater ecosystems. Journal of the North American Benthological Society, 29(1): 264-285.

Boulton AJ, Brock MA, Robson BJ, Ryder DS, Chambers JM, Davis JA. 2014. Australian Freshwater Ecology. Process and Management (Second Edition). USA: John Wiley \& Sons, Ltd.

BPS Kabupaten Bogor. 2019. Kabupaten Bogor dalam Angka 2019. Bogor: BPS Kabupaten Bogor.

Butakka CMM, Grzybkowska M, Pinha GD, Takeda AM. 2014. Habitats and trophic relationships of Chironomidae insect larvae from the Sepotuba River basin, Pantanal of Mato Grosso, Brazil. Brazilian Journal of Biology. 74 (2): 395-407.

Choudhary A, Ahi J. 2015. Biodiversity of Freshwater Insects: a Review. The International Journal of Engineering and Science. 4(10): 25-31.

Clifford FH. 1991. Aquatic Invertebrate of Alberta. Canada: The University of Alberta press.

Desai AS, Khamkar AG, Sathe TV. 2015. Ecology and Ethology of Crane fly Tipula paludosa Meigen (Tipulidae: Diptera) from Kolhapur region, India. Biolife. 3(1):21-25.

DIT PEPDAS. 2015. Peta Citra SRTM DAS Cisadane Provinsi Banten dan Jabar. Diakses di http://sipdas.menlhk.go.id/maps/? limit $=100 \&$ offset $=0$ pada tanggal 16 Desember 2019.

Fisher SG, Gray LJ. 1983. Secondary Production and organic matter prosessing by collector macroinvertebrates in a desert stream. Ecology. 64(5): 1217-1224.

Floss ECS, Secretti E, Kotzian CB, Spies MR, Pires MM. 2013. Spatial and temporal distribution of non-biting midge larvae assemblages in streams in a mountainous region in Southern Brazil. Journal of Insect Science. 13: 1-27.

Fusari MF, Dantas GPS, Pinho LC. 2018. Chapter 16 Order Diptera. In: Keys to Neurotropical Hexapoda.Thorp and Covich's Freshwater. (Fouth Edition. Volume III) UK: Elsevier Inc.

Hamada N, Thorp JH, Rogert DC. 2018. Keys to Neurotropical Hexapoda. Thorp and Covich's Freshwater.(Fouth Edition.Volume III) UK: Elsevier Inc.

Hirabayashi K, Fukanaga Y Mishima T. 2007. Distribution pattern of Craneflies (Diptera Tipulidae) in the upper and middle reaches of the Shinano River in Central Japan. Journal of Freshwater Ecology. 22(2): 319-324. . 
Hynes H BN, Coleman MJ. 1968. A simple method of assessing the annual production of stream benthos. Limnology and Oceanography. 13:569-573.

Junaidi E. 2014. Hasil air penggunaan lahan hutan dalam menyumbang aliran sungai. Jurnal Hutan Tropis. 2(1): 1-8.

Kawai K, Hara S, Saito H. 2014. Usefulness of Chironomid larvae as physicochemical and biological indicators. a case study of the mountainous streams in the Gono River System. Bulletin of the Hiroshima University Museum. 6: 7-13.

Kranzfelder P, Ferrington JrLC. 2018. Chironomidae (Diptera) species diversity of estuaries across a land use gradient on The Caribbean Coast of Costa Rica. Revista de Biología Tropical (International Journal of Tropical Biology and Conservation). 66(3): 1118-1134.

Kriska G. 2014. Freshwater invertebrate in Central Europe. A Field Guide. Vienna: Springer.

Mackey AP. 1977. The growth and development of larval Chironomidae (Diptera). Oikos. 28: 270-275.

Majagi S, Parameshwara BS, Vijaykumar, K. 2003. Estimation of secondary productivity of aquatic insects at Jagath Tank, Gulbarga. Seminar on Environment Management and Pollution Control. 88-90.

Moss B. 2018. Ecology of Freshwater Earth's Bloodstream (Fifth Edition). UK: John Wiley \& Sons Ltd.

Priyono A. 2012. Biota perairan di area pertambangan emas PT. Natarang Mining, Lampung Selatan. Media Konservasi. 17(1): 1622.

Rossi LAL, Saito VS, Santino MBC, Strixino ST. 2015. How does leaf litter chemistry influence its decomposition and colonization by shredder Chironomidae (Diptera) larvae in a tropical stream?. Hydrobiologia. 1-13.

Scheibler EE, Juñent SAR, Claps MC. 2014. Chironomid (Insecta: Diptera) assemblages along an Andean altitudinal gradient. Aquatic Biology. 20:169-184.

Solanki R, Shukla A. 2015. Aquatic insects for biomonitoring freshwater ecosystems: A report. International Journal of Science and Research. 6(2): 2056-2058.

Townsend CR, Begon M, Harper JL. 2008. Essentials of Ecology (Third Edition). USA: Blackwell Publishing.

Wetzel RG. 2001. Limnology Lake and River Ecosystems (Third Edition). USA: Academic Press. 